Article

\title{
Business Model Design for Latecomers in Biopharmaceutical Industry: The Case of Korean Firms
}

\author{
Changhyeon Song ${ }^{1}(\mathbb{D})$ and Kwangsoo Shin ${ }^{2, *}$ \\ 1 Technology Management Economics and Policy Program, College of Engineering, Seoul National University, \\ Gwanak-ro 1, Gwanak-gu, Seoul 08826, Korea \\ 2 Department of Biomedical Convergence, College of Medicine, Chungbuk National University, \\ Chungdae-ro 1, Seowon-gu, Cheong-ju, Chungbuk 28644, Korea \\ * Correspondence: sksidea@gmail.com or sksidea@chungbuk.ac.kr; Tel.: +82-43-261-2858
}

Received: 8 August 2019; Accepted: 3 September 2019; Published: 6 September 2019

\begin{abstract}
Given high business risks and interdependency with various organizations in biopharmaceutical industry, business model has become a key element for firms that aim to be more sustainable and profitable. Despite its growing importance, research on the business model design in biopharmaceutical industry is limited. In particular, there is a lack of research dealing with business models or strategies for latecomers. In the face of drastic changes such as market expansion and patent expiration, there has been growing interest in latecomer's business model in the biopharmaceutical industry. This study identifies different types of business model designs using hierarchical clustering. Based on an empirical study of 313 biopharmaceutical firms in Korea, we find three types of business models: business diversified research firm, non-diversified research firm, and mature firm. We then compare the general characteristics and performances of each cluster. The findings indicate that business diversification of biopharmaceutical firms is beneficial in terms of profit. This implies that the biopharmaceutical firms in latecomer countries such as Korea are recommended to consider business diversification for sustainable management.
\end{abstract}

Keywords: business model; biopharmaceutical industry; latecomers; business sustainability; hierarchical clustering

\section{Introduction}

In a rapidly changing business environment, firms' competitive focus has shifted from competition of product or technology to that of overall business model. This shift suggests that the business model is becoming more critical to creating competitive advantages and identifying business opportunities [1]. In some industries where competition has lasted for long period, there is a tendency to sustain through the differentiation of the business model. This is also the case for the biopharmaceutical industry which faces several barriers including technological (patent expiration and constant technological advances), market (pricing), and governmental (reimbursement) challenges [2,3]. Given high business risks and interdependency with various organizations with complementary assets, the importance of business model in biopharmaceutical industry has been emphasized [4,5]. It is also revealed that business model innovation in this industry provoke subsequent innovations [6]. Therefore, the discussion of business models in biopharmaceutical industry is of considerable importance.

However, the strategy for latecomers have not been extensively studied in existing business model literature. Especially in science-intensive industries such as biopharmaceutical industry, it is not easy for latecomers to sustain a business because they lack technological capabilities, organizational learning as well as responding to regulatory inquiries [7]. For this reason, the hegemony of leading companies 
in the biopharmaceutical industry has hardly changed compared to other industries. In recent years, however, the patents of major blockbuster products have expired, resulting in opening the window of opportunity for latecomers. New countries such as India, Brazil, and Thailand entered the market in a stream which caused upheavals in the industry [8]. In order for them to sustain their business and eventually grow, they should choose the right strategy as a latecomer. Therefore, the sustainable business model for latecomers needs to be discussed further in an era of global competition. Though research on business model innovation for sustainability has begun to be developed [9-11], the studies that focused on the latecomer's point of view are still rare.

To propose a business model for latecomers in biopharmaceutical industry, two issues below should be considered. First, the design of business model should evolve dynamically in accordance with a changing business environment $[12,13]$. In addition, technological advances and business models co-evolve to generate value [14]. Although previous studies tried to evince diverse definition and component at a rudimentary level, the concept of business model still remain ambiguous. According to the existing discussions, the business model can be defined as a methodological concept of how firms can generate and deliver values [12]. It is also a strategic plan, with choices and devices for generating technological innovation and financial performance such as patent, revenue, or profit [1,15-19]. Because of the ambiguity of the concept, there is no clear set of criteria for classifying the business model. Previous studies on business models in the biopharmaceutical industry showed that the vertical integration in value chain and business diversification were traditionally important components for business model portfolio [20-22]. However, because of rapidly increasing R\&D costs and declining productivity and profitability as well as firm's strategic plan for sustainable growth, strategic alliance has been emphasized recently. This means that there is an increasing need for a business model that forms a network with various organizations through strategic alliances within the value chain. Nonetheless, there are few studies on business model of biopharmaceutical industry in integrated view including vertical integration in industrial value chain, business diversification, and strategic alliance.

Second, the quantitative approach for the classification of business model in biopharmaceutical industry is required. Although many discussions on the concept of business model have been made, there are still few studies that attempted empirical classification [23]. The same goes for the biopharmaceutical industry. Most previous studies on business model in biotechnology industry analyzed exemplary cases of certain firms and conceptualized these to propose the novel types of business model. Although those studies provided a little evidence regarding business model of biotechnology industry through qualitative analysis, there is a limitation to represent the features of the whole industry. Therefore, identifying business models through quantitative methods and comparing the performance of each will help to identify the overall trend.

This study aims to quantitatively identify various patterns of business model design in biopharmaceutical industry and compares the performance of those models to suggest appropriate strategies for latecomers catching up the industry leader. Korea is considered as a latecomer in the biopharmaceutical industry compared to the US, Japan, and several European countries such as Germany and UK. Recently, some companies such as Hanmi or Celltrion have made considerable progress, but the industry as a whole is still lagging behind. Therefore, it is expected to provide implications for latecomers by analyzing the Korean case.

This study is structured as follows. Section 2 introduces the concept of strategy and business model and link it to the discussion of industry latecomer. Then the types of business model in biopharmaceutical industry is summarized. Section 3 deals with the data and analytical method. Section 4 as result section, identifies patterns of business model of Korean biopharmaceutical firms and defines their business models. Further discusses the characteristics and performances of them. Section 5 provides implications and limitations of this study. 


\section{Business Model and Biopharmaceutical Industry}

\subsection{Strategy and Business Model for Latecomers}

Business models, especially the design and innovation of them, are emerging trends in academia and practice [24]. Although there is no complete agreement on the concept of business model, it is generally considered as a plan, tool or device for exploiting the economic value $[1,5,18]$. The concept of business model and firm's strategy are often used interchangeably. The former, however, is rather an abstract and comprehensive framework for realizing the latter. Depending on the combination of business models, multiple strategies are no longer a matter of choice. Strategies can be derived from dual business models resulted from similarities and conflicts between the established and innovative industry [25]. Even paradoxical strategies are pursued simultaneously by complex business model portfolios [26]. In other words, the business model is the plan to adopt various strategies and it makes competitive choices possible [1]. In addition, business models should embrace the revenue-generating strategies for the business sustainability. Therefore, the business model is considered to be an innovation device that is close to market compared to a general strategy $[27,28]$.

This distinction is important in the discussions on the latecomers. Although there are many studies on the catch-up strategies for latecomer firms [29-31], those on the business model are rare. In particular, catch-up by latecomers is known to be more difficult in biopharmaceutical industry compared to other high-tech industries such as information and communication technology industry [31]. Korean biopharmaceutical firms are sandwiched between innovative firms in major advanced countries and latecomers in large emerging countries such as China and India [32]. The mid-sized latecomer countries are hard to have comprehensive biopharmaceutical innovation system. Moreover, the latecomers in this country do not have a large domestic market and cheap labor as well as overwhelming technological capabilities. They need a proper business model for sustainable growth.

On the one hand, the profitability is crucial to the sustainability of biopharmaceutical industry. Even in the US, where the industry is at the forefront, the lack of profitability was a potential concern that could impede the growth of industry [4]. Lazonick and Tulum [33] argued that US biopharmaceutical industry was able to attract sufficient investment despite the difficulties in realizing profits due to the sound capital markets and government-led research outcomes. Latecomer countries, however, generally have less developed capital markets, so the exit strategies of venture capitals through initial public offerings (IPOs) or merger and acquisitions (M\&A) are hard to achieve. There is a tendency for government support to public R\&D is small in latecomer countries. Hence, profit model based on the earnings and costs should be considered in the business model literature [34].

In order to suggest the appropriate design for latecomers, it is necessary to organize the discussions on the business model in biopharmaceutical industry. Various business models unique to the biopharmaceutical industry are presented [5].

\subsection{Business Models of Biopharmaceutical Industry}

Previously discussed studies on business model in (bio)pharmaceutical industry is mainly based on a firm's operational role in value chain and the level of business diversification. In a combined perspective of both operational role in value chain and business diversification, many scholars tried to classify the business models in biotechnology firms [20,21,35-37].

First, there are the following classifications according to their positions in the value chain. The business models in the biopharmaceutical industry traditionally have been divided into two models: (1) a model in which a small firm transfers technology to large pharmaceutical firms, and (2) another model of large pharmaceutical firms based on the vertical integration of R\&D, clinical tests, approval, product manufacturing and marketing [38]. Burns [39] also segmented business models in the biotechnology industry according to operational role in value chain, including RIBCO (research intensive bio-pharmaceutical company), the technology platform model, NRDO (no research, development only) and FIBCO (fully integrated bio-pharmaceutical company). The RIBCO model 
refers to a type of firm specializing in R\&D and generating profits through technological performance in a basic R\&D or product development processes. In such a business model, a firm conducts clinical tests on new drug candidate substance and licenses to pharmaceutical companies, then reinvests the royalty profits generated from this into R\&D. Second, the technology platform model refers to a type of firms that increases product efficacy in the R\&D stage of biotechnology products and adds value in technology by providing platform technologies to ultimately generate profit. There have been steady efforts to standardize a series of processes related to culture, refinement and analysis, and because of such efforts, platform technologies have been developed in the biotechnology industry. Third, the NRDO model refers to a type of firm developed solely through licensing, with its entire product pipeline being from the outside (other biotechnology firms and pharmaceutical firms). Because of R\&D risk reduction, sales and profit increases are critical for these biotechnology firms, this type of firm concentrates on the development related to profit materialization areas instead of on initial R\&D. Last, the FIBCO model is a type of firms that are traditional pharmaceutical firms conducting business activities encompassing $R \& D$, manufacturing and marketing.

Second, the business model in biopharmaceutical industry has also been classified regarding the level of business diversification. Casper [40] classified the biotechnology industry into a therapeutic product segment and a platform and service segment. The platform and service segment plays a role not only in the value chain independently but also in different business segments. With the platform and service sector, the business model portfolio of the biopharmaceutical industry has further expanded [22,41]. There are many examples of business diversification in the biopharmaceutical industry. Firms founded since the early 1980s in Europe are biotechnology firms concentrating on developing therapeutic products. However, they started to enter the platform and service area in the late 1980s, and the hybrid business model encompassing both therapeutic product and platform and service area appeared in the early 1990s [42]. Firms with hybrid business models are reported to attract more investment than those with a single business sector because of their reduced risks and increased expected return on investment. Some scholars argued that biotechnology firms should secure revenue streams through related business diversification because they have high interdependencies within the same industry and R\&D process of biomedicine and diagnostic kits and reagents are risky $[4,5,36]$.

Meanwhile, in accordance with the worsening productivity and profitability of biotechnology firms as well as rising demand for strengthening core competitiveness, the other types of business model have been requested [43]. In particular, a fully integrated model which is typical in large pharmaceutical firms is considered to be no longer a sustainable one [44]. Therefore, a cooperative business model where various functional organizations in value chain collaborate with one another through strategic alliances has been emphasized [36,45]. In this model, a large portion of corporate activities is outsourced. Downs and Velamuri [46] identified areas of opportunity through extensive reviews of the business model literature in the biopharmaceutical industry, one of which is external orientation. For example, the main business area of CRO (contract research organization), CMO (contract manufacturing organization) and CSO (contract sales organization) which are subset of FIBCO business model is the collaboration with other firms [47]. They can acquire complementary assets through strategical alliances and it helps to reduce business risks and strengthen the core competitiveness. This is also linked to the discussion of open innovation in the biopharmaceutical industry [48]. In this industry, open innovation spans a wide range of activities from drug discovery through data sharing to product development and clinical test platforms [49]. Mazzola et al. [50] empirically tested that open innovation is actually beneficial to firms' performance in biopharmaceutical industry. Moreover, open innovation strategies are indispensable for latecomers in this industry [51].

Combining above discussions, business models discussed in the biopharmaceutical industry are shown in Figure 1.

In sum, these features including the operational role in value chain, the level of business diversification and the level of strategic alliance should be important criteria for classifying business model. However, previous studies failed to comprehensively consider these three aspects. Therefore, 
our study considers them as grouping variables that are critical criteria for classifying business model in biopharmaceutical industry. Although there are various types of strategic alliances, we only consider the two types of them, $R \& D$ (research and development) and $M \& M$ (manufacturing and marketing) alliances. Even though there may exist more criteria for classifying business models, these three categories are considered the most significant especially in the biopharmaceutical industry.

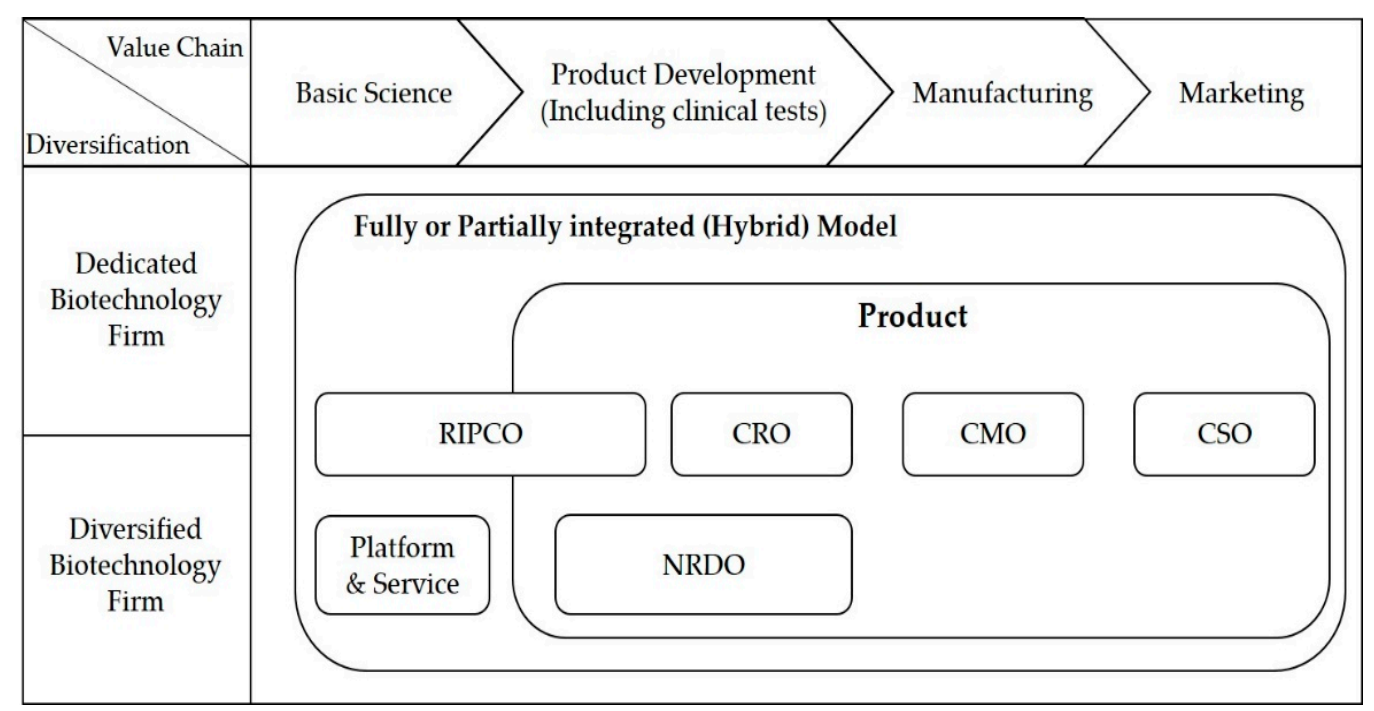

Figure 1. The business models in biopharmaceutical industry.

\section{Data and Methods}

\subsection{Data}

This study used the bio venture database of the Science and Technology Policy Institute (STEPI) of the Republic of Korea [52]. The database confirmed that 2441 bio ventures existed in Korea from 1992 to 2012, referring to firms introduced in the "Guide to Biotechnology Companies in Korea" issued by the Korea Biotechnology Industry Organization in 2012, conducted in the National Science and Technology Information Service DB. Among them, 1504 bio ventures were finally confirmed, excluding foreign firms and firms specialized in importing and sales without technological innovation activities. The bio ventures span a wide range of area including food, chemistry and energy etc. In this study, only companies in the pharmaceutical as well as platform and services sectors were selected to represent the biopharmaceutical industry. As a result, 313 bio venture firms were selected for analysis.

The size, age, and core business area of the target firms for analysis are shown in Table 1. There were 270 companies $(87.6 \%$ ) categorized as small because they employed fewer than 50 people. The number of firms under 10 years old was $162(51.8 \%)$. Among the total number of firms, $211(67.4 \%)$ were considered therapeutic product-oriented firms and were made up of 169 bio-medicine and 42 diagnostic kits and reagents manufacturing firms. There were 102 infrastructure firms (32.6\%); 83 of them featured supporting services, and 19 offered measurement and analysis equipment.

Table 1. General features of Korean biopharmaceutical firms in 2011.

\begin{tabular}{lcc}
\multicolumn{1}{c}{ Characteristics } & Number of Firms & Percentage \\
\hline Firm size (number of employees) & & \\
Small $(<50)$ & 270 & 86.3 \\
Medium $(51-100)$ & 43 & 13.7 \\
Large $(>100)$ & 0 & 0 \\
Firm age (years since foundation) & 162 & 51.8 \\
Young $(<10)$ & 151 & 48.2 \\
Established $(>10)$ & & \\
\hline
\end{tabular}


Table 1. Cont.

\begin{tabular}{lcc}
\hline \multicolumn{1}{c}{ Characteristics } & Number of Firms & Percentage \\
\hline Type of main product and service & & \\
Bio-medicine & 169 & 54.0 \\
Diagnostics kit and Reagent & 42 & 13.4 \\
Supporting services & 83 & 26.5 \\
Measurement and Analysis equipment & 19 & 6.1 \\
\hline Total & 313 & 100.0 \\
\hline
\end{tabular}

\subsection{Analytical Method}

This study adopted the hierarchical clustering method to find clusters in biopharmaceutical industry in Korea using the level of vertical integration, business diversification, and strategic alliance as the criteria. Hierarchical clustering is a methodology for identifying clusters based on the similarities between observed values. The hierarchy is determined sequentially according to the level of similarity. These process can be visualized in the form of tree branch.

Hierarchical cluster analysis is categorized as follows according to the way of measuring the distance between clusters: single linkage method, complete linkage method, centroid linkage method, average linkage method, median linkage method and Ward's method. This study used Ward's method which integrates clusters by minimizing the square error of Euclidean distance between objects comprising a cluster [53]. This method is known to classify clusters smaller and more even than other clustering methods [54].

Most biopharmaceutical firms are small. Hence, there is great concern for data bias regarding clustering features. In such cases, other clustering methods tend to divide into two clusters, one with outstanding performance and the other without. To avoid this problem, the Ward's method was used in this study [54].

To determine the business model types for biopharmaceutical firms in Korea, this study conducted cluster analysis based on the following grouping variables which was presented in Table 2: (1) basic science, (2) product development, (3) manufacturing and marketing, (4) level of diversification, (5) level of R\&D alliance, (6) level of M\&M alliance.

Table 2. Grouping variables and operational definition.

\begin{tabular}{ll}
\hline \multicolumn{1}{c}{ Grouping Variables } & \multicolumn{1}{c}{ Operational Definition } \\
\hline Basic science & 1 if firm has basic research function, 0 otherwise \\
\hline Product development & 1 if firm has product development function, 0 otherwise \\
\hline Manufacturing and marketing & 1 if firm has manufacturing and marketing function, 0 otherwise \\
\hline Level of business diversification & The number of business area \\
\hline Level of R\&D alliances & The number of R\&D alliances from 2005 to 2011 \\
\hline Level of M\&M ${ }^{1}$ alliances & The number of M\&M alliances from 2005 to 2011 \\
\hline
\end{tabular}

First, this study examined the distribution of each firm's business functions in a value chain. The value chain in the biopharmaceutical industry can be divided into four broad stages: (1) basic science, (2) product development, (3) manufacturing, and (4) marketing [22]. However, firms only specialized in importing and sales without technological innovation activities in sample for this study was excluded. Then, this study only defined three business functions in value chain: (1) basic science, (2) product development, (3) manufacturing and marketing. Therefore, this study includes three grouping variables, depending on operational role in value chain.

Second, this study investigated firms' business diversification. For the biotechnology industry, business areas can be divided into four types: (1) red-bio related to pharmaceutical, (2) green-bio 
related to food, (3) white-bio associated with the cosmetic, functional material or energy industry, and (4) platform and service related to specialized platform technology or services such as cell culture, refinement and analysis [52,55]. Therefore, this study used the number of business areas that biopharmaceutical firm engaged in the four biotechnology sectors as proxy of the level of business diversification.

Third, this study examined R\&D and M\&M alliances. R\&D alliances included R\&D collaborations, technology transfers, and commissioned R\&D; in addition, M\&M alliances included commissioned manufacturing alliances and marketing alliances. However, strategic alliances in the Korean biopharmaceutical industry are not as active as in developed countries as yet. Because of such data features, in the analysis based solely on 2011 data, strategic alliance characteristics are highly likely to be omitted. Thus, this study determines the level of R\&D and M\&M alliance based on the number of strategic alliances from 2005, when data research was started, to 2011.

However, having different absolute value ranges, these variables should normalize. If these variables are used in clustering analysis without normalizing, the variable with the larger range influences more important role of classifying the objects. Therefore, this study used z-score transformation for normalizing criteria variables, which measures how far the object is from the average value using the unit of standard deviation.

After clustering analysis, this study confirms equality in variables among clusters, and contrast them between paired clusters. For these, this study uses Kruskal-Wallis equality test and Mann-Whitney test as its ad-hoc test, because the variables in this study did not follow the normal distribution. First, Kruskal-Wallis equality test is non-parametric method for comparing equalities among groups. The Kruskal-Wallis test is a multiple-sample generalization of the two sample Mann-Whitney rank sum test $[56,57]$.

\section{Results and Discussions}

\subsection{The Groups of Korean Biopharmaceutical Firms}

Figure 2 describes a dendrogram, which is a tree diagram for arrangement of clusters produced by hierarchical clustering. The horizontal axis in the dendrogram indicates groups while vertical axis represents dissimilarity between clusters. As shown in Figure 2, biopharmaceutical firms in Korea can be classified into multiple numbers of clusters through statistical analysis. There is no definitive answer regarding the optimal number of clusters because hierarchical clustering analysis is an exploratory approach [20,58].

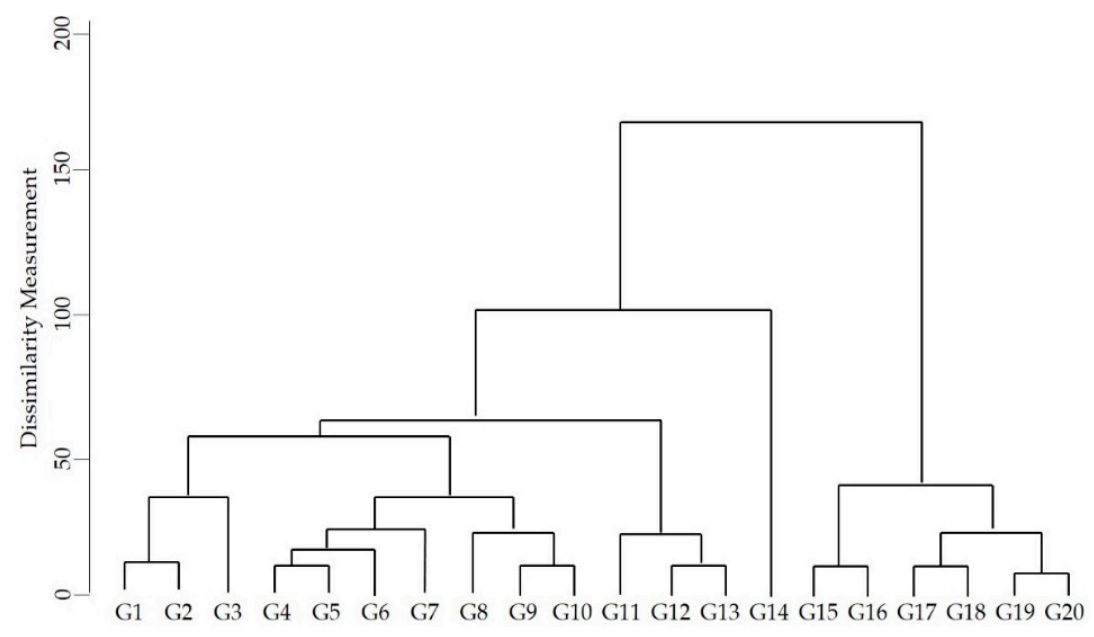

Figure 2. Dendrogram from hierarchical cluster analysis. 
Since there are six grouping variables, 64 different business model combinations are theoretically possible. In practice, however, fewer combinations are feasible because each grouping variable is not independently applied and the number of samples is not much enough. In this study, we focus on identifying clusters with the most significant differences based on three categories mentioned above: positions in the value chain, business diversification, strategic alliances.

Figure 3 describe decision tree for classifying clusters. It represents that cluster 1 gradually decided by non-product development function, more business diversification level, less R\&D alliance level, basic science function, and cluster 2 by the non-product development function, less business diversification level, less M\&M alliance level, less R\&D alliance level. However, cluster 3 was decided by various combinations. First, biopharmaceutical firm with product development function classified to cluster 3 . Second, though they don't have product development function, they included in cluster 3 with high business diversification and R\&D alliance level. Third, though they do not have product development functions and high R\&D alliance level, they included in cluster 3 with high business diversification and non-basic research function such as product development, manufacturing and marketing. Fourth, though they don't have product development function and high business diversification, they included in cluster 3 with high M\&M alliance level. Fifth, though they don't have product development function and high business diversification and M\&M alliance level, they included in cluster 3 with high $R \& D$ alliance level.

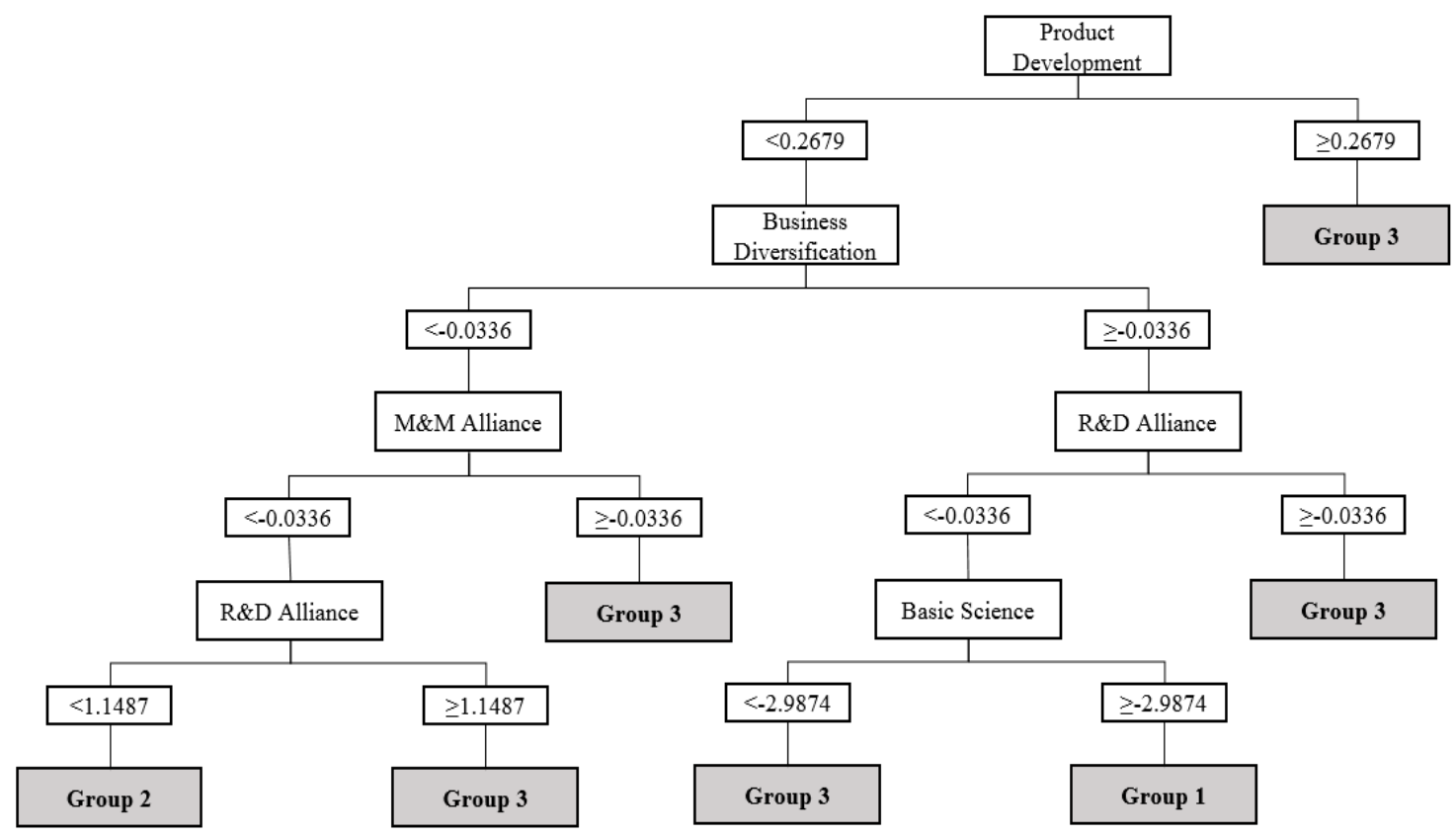

Figure 3. Decision tree for classifying clusters.

According to the above classification, many different groups are included in cluster 3 . However, there are only few firms in each group and there is not much difference between them compared to the differences with cluster 1 and 2. Nevertheless, it is clear that cluster 3 is a relatively heterogeneous cluster. Table 3 describes the number of biopharmaceutical firms by cluster. Clusters 1, 2 and 3 include $68(22 \%), 110(35 \%)$ and 135 (43\%) firms, respectively. Cluster 3's size is the largest, followed by cluster 2 , then cluster 1 . The descriptive statistics of grouping variables for business model design is also as shown in Table 3. In addition, this study performed Kruskal-Wallis equality test for confirming significant differences in grouping variables among clusters. This study represents that product development, the level of business diversification, the level of $R \& D$ alliance are significant variables that discriminate the characteristics of biopharmaceutical firms in Korea in Table $3(p<0.01, p<0.01$, $p<0.05)$. 
Table 3. Descriptive statistics of grouping variables and the results of Kruskal-Wallis, Mann-Whitney test.

\begin{tabular}{|c|c|c|c|c|c|c|c|c|}
\hline \multirow[b]{2}{*}{ Criteria } & \multicolumn{4}{|c|}{ Descriptive Statistics } & \multirow{2}{*}{$\begin{array}{c}\text { Significant Differences } \\
\chi^{2}\end{array}$} & \multicolumn{3}{|c|}{ Mean Differences between Paired Clusters } \\
\hline & $1(N=68)$ & $2(N=110)$ & $3(N=135)$ & Total & & 2 vs. 1 & 3 vs. 1 & 3 vs. 2 \\
\hline Basic science & $1.00(0.20)$ & $1.00(0.00)$ & $0.94(0.24)$ & $0.97(0.16)$ & 0.81 & 0.00 & $-0.06^{* *}$ & $-0.06^{* *}$ \\
\hline Product development & $0.00(0.00)$ & $0.00(0.00)$ & $0.86(0.55)$ & $0.37(0.48)$ & $169.51^{* * *}$ & 0.00 & $0.86^{* * *}$ & $0.86^{* *}$ \\
\hline Manufacturing and Marketing & $0.00(0.00)$ & $0.00(0.00)$ & $0.14(0.35)$ & $0.06(0.24)$ & 4.55 & 0.00 & $0.14 * * *$ & $0.14^{* * *}$ \\
\hline Level of business diversification & $2.34(0.59)$ & $1.00(0.00)$ & $1.54(1.68)$ & $1.52(0.72)$ & $130.39 * * *$ & $-1.34^{* * *}$ & $-0.80^{* * *}$ & $0.54^{* * *}$ \\
\hline Level of $R \& D$ alliances & $0.00(0.00)$ & $0.00(0.00)$ & $0.21(0.52)$ & $0.09(0.36)$ & $7.26^{* *}$ & 0.00 & $0.21^{* * *}$ & $0.21^{* * *}$ \\
\hline Level of M\&M alliances & $0.00(0.00)$ & $0.00(0.00)$ & $0.26(0.72)$ & $0.11(0.49)$ & 4.55 & 0.00 & $0.26^{* * *}$ & $0.26^{* * *}$ \\
\hline
\end{tabular}

Note: The value in parenthesis are standard deviation. ${ }^{* * *} p<0.01,{ }^{* *} p<0.05,{ }^{*} p<0.1$. 
Furthermore, this study performed the Mann-Whitney test for contrasting in grouping variables between paired clusters as post hoc analysis of Kruskal-Wallis equality test. Table 3 shows that there are differences on criteria among each cluster. Biopharmaceutical firms of cluster 3 with product development function are more than those of cluster $1,2(p<0.01, p<0.05)$. Biopharmaceutical firms of cluster 1 on the level of business diversification are larger than those of cluster $2,3(p<0.01, p<0.01)$, and those of cluster 3 are also larger than those of cluster $2(p<0.01)$. Finally, biopharmaceutical firms of cluster 3 on the level of R\&D alliance are larger than those of cluster $1,2(p<0.01, p<0.01)$.

In sum, clusters 1 and 2 includes only basic research firms in infant stage, but firms of cluster 1 is the higher level of business diversification than those of cluster 2. Therefore, this study named cluster 1 "business diversified research firms", cluster 2 "non-diversified research firms". It means that biopharmaceutical firms in Korea are generated from the type of dedicated firms or business diversified firms. For example, firm $H$ which have competitiveness in new bio-medicines such as stroke and premature ejaculation treatment expanded its business portfolio with functional cosmetics. Another research-oriented firm $O$ which dedicated to bone-related new medicines also developed functional food using ginseng. These firms primarily focus their effort on developing therapeutics but they also pursue business diversification for profit generation and survival. In comparison with it, biopharmaceutical firms of cluster 3 generally include functions of basic science, product development, and some include that of manufacturing and marketing. The firms in cluster 3 are mature so they can generate revenue by technology and product. They also ally with other organizations for R\&D, manufacturing, or marketing and strategically diversifies their business areas. Therefore, we named cluster 3, "mature firms".

\subsection{The Characteristics and Performances of Each Cluster}

The characteristics and performances of each identified clusters were compared. First, this study considers characteristic variables as firm's size, age, government $R \& D$ funding and $R \& D$ intensity. The size of the firm is defined as the number of employees. The age, on the other hand, is defined as the number of years since foundation. The government R\&D funding consist of both total government R\&D fund and the total number of government $R \& D$ projects. R\&D intensity was measured by the ratio of R\&D expenditure to the number of employees. Second, this study compared the technological innovation and financial performance of each cluster. The number of patents represent technological innovation performance [59], and revenues, operating profit, net profit are used as a financial performance [60]. The descriptive statistics of characteristics and performance variables in each cluster are described in Table 4.

The results of Kruskal-Wallis equality test in Table 4 show that there exist differences between at least one pair of clusters in all variables. Furthermore, the results of Mann-Whitney test between paired clusters in Table 4 demonstrate that there are differences among all characteristic and performance variables. According to Table, firms in cluster 3 are larger and older than those in clusters 1 and 2 $(p<0.01, p<0.01$ each). They also performed the more number of government R\&D projects than those of cluster $2(p<0.01)$ and received more government R\&D funding than firms in cluster 1 and $2(p<0.01, p<0.01$ each). Furthermore, they recorded higher R\&D intensity than those in cluster $2(p<0.1)$, and higher technological innovation performance than those in cluster 1 and $2(p<0.05$, $p<0.05$ each). This implies that firms in cluster 3 maintain relatively high R\&D input and output for their core technology and product. Finally, cluster 3 also showed superior financial performance. Revenue is higher in cluster 3 than clusters 1 and $2(p<0.01, p<0.01$ each), while operating profit and net profit in cluster 3 is higher than only cluster $2(p<0.05)$. There is no significant difference between cluster 1 and cluster 3 in operating profit and net profit, in spite of significant difference in revenue. This is partially due to the higher operating and labor costs of mature firms which are generally larger than research-oriented firms. In any case, difference between the results of clusters 1 and 2 shows that business diversification strategy is a critical factor to secure profit. 
Table 4. Descriptive statistics of characteristics and performance variables, and the results of Kruskal-Wallis, Mann-Whitney test.

\begin{tabular}{|c|c|c|c|c|c|c|c|c|}
\hline \multirow[b]{2}{*}{ Criteria } & \multicolumn{4}{|c|}{ Descriptive Statistics } & \multirow{2}{*}{$\begin{array}{c}\begin{array}{c}\text { Significant } \\
\text { Differences }\end{array} \\
\chi^{2}\end{array}$} & \multicolumn{3}{|c|}{ Mean Differences between Paired Clusters } \\
\hline & $1(N=68)$ & $2(N=110)$ & $3(N=135)$ & Total & & 2 vs. 1 & 3 vs. 1 & 3 vs. 2 \\
\hline Size & $7.56(16.66)$ & $17.47(17.30)$ & $31.85(22.49)$ & $23.69(20.79)$ & $47.13^{* * *}$ & $-0.09^{* * *}$ & $14.29^{* * *}$ & $14.38^{* * *}$ \\
\hline Age & $9.07(4.27)$ & $8.33(4.61)$ & $12.39(7.37)$ & $10.24(6.19)$ & $35.91 * * *$ & $-0.75 * * *$ & $3.32 * * *$ & $4.07^{* * *}$ \\
\hline Total gov R\&D fund & $188.60(323.12)$ & $120.50(210.50)$ & $411.01(616.88)$ & $260.59(468.16)$ & $15.60 * * *$ & $-68.10^{* * *}$ & $222.41^{* * *}$ & $290.51 * * *$ \\
\hline Number of gov R\&D project & $0.94(1.13)$ & $0.67(0.94)$ & $1.21(1.32)$ & $0.96(1.18)$ & $9.21 * * *$ & -0.27 & 0.27 & $0.54^{* * *}$ \\
\hline R\&D intensity & $57.00(68.69)$ & 68.24 (97.72) & $152.24(451.20)$ & $102.03(306.14)$ & $5.37 *$ & 61.24 & 95.24 & $84.00 *$ \\
\hline Patent & $0.28(0.79)$ & $0.32(0.88)$ & $0.78(1.76)$ & $0.51(1.34)$ & $3.35 *$ & 0.04 & $0.50 * *$ & $0.46^{* *}$ \\
\hline Revenue & $6.5 \times 10^{6}\left(2.2 \times 10^{7}\right)$ & $3.1 \times 10^{6}\left(6.5 \times 10^{6}\right)$ & $1.9 \times 10^{7}\left(2.7 \times 10^{7}\right)$ & $1.1 \times 10^{7}\left(2.2 \times 10^{7}\right)$ & $78.38^{* * * *}$ & $-3.4 \times 10^{6}$ & $1.2 \times 10^{7 * * *}$ & $1.5 \times 10^{7 * * *}$ \\
\hline Operating profit & $2.5 \times 10^{7}\left(1.3 \times 10^{6}\right)$ & $7.4 \times 10^{4}\left(1.0 \times 10^{6}\right)$ & $1.1 \times 10^{6}\left(4.7 \times 10^{6}\right)$ & $5.6 \times 10^{5}\left(3.3 \times 10^{6}\right)$ & $20.36^{* * *}$ & $-1.8 \times 10^{5}$ & $8.5 \times 10^{5}$ & $1.0 \times 10^{6 * *}$ \\
\hline Net profit & $1.9 \times 10^{5}\left(9.8 \times 10^{5}\right)$ & $5.5 \times 10^{4}\left(9.8 \times 10^{5}\right)$ & $4.5 \times 10^{5}\left(4.7 \times 10^{6}\right)$ & $2.6 \times 10^{5}\left(3.2 \times 10^{6}\right)$ & $7.95^{* *}$ & $-1.4 \times 10^{5}$ & $2.6 \times 10^{5}$ & $4.0 \times 10^{5 * *}$ \\
\hline
\end{tabular}

Note: The value in parenthesis are standard deviation. ${ }^{* * *} p<0.01,{ }^{* *} p<0.05, * p<0.1$. 


\section{Conclusions}

The science-based, technology-intensive characteristics and high business risk in clinical trials, approval, manufacturing and marketing in the biopharmaceutical industry require a variety of strategies for biopharmaceutical firms. For these reasons, the business model design of biotechnology firms is very important for implementing competitive strategy, and should be continuously changed for their survival. This study aimed to identify the business models of biopharmaceutical firms in Korea by quantitatively classifying firms using a clustering analysis method and to observe their characteristics and performance. This study found that biopharmaceutical firms in Korea could classify both infant firms with basic research function, which also classified by business diversification level, and mature firms. In addition, mature biopharmaceutical firms in Korea had various business models, and higher technological innovation and financial performance with relatively larger value in the aspects of size, age, government $R \& D$ fund, $R \& D$ intensity.

Based on these results, this study suggests three implications. First, product development function is critical factor for biopharmaceutical firm's survival. Most important grouping variable for classifying Korean biopharmaceutical firms was product development. Biopharmaceutical firms of cluster 3, which has high distribution to product development, ultimately have better technological innovation and financial performance. In present, there are biopharmaceutical firms in the Korea with only basic research function. This study suggests that they should make efforts to consider opportunities for commercialization to achieve initial growth, although they are now basic research firms. By securing profit by commercializing their technologies and products, or providing services for basic $R \& D$ (ex. services using platform technology such as bioinformatics) at the initial stage, they should evolve to partially or fully integrated firms.

Second, business diversification strategy can reduce risk by securing revenue from other business area in the initial stage, in comparison with that of dedicated biotechnology firm type in the context of biotechnology latecomer such as Korea. This study proved that there is no significant difference between cluster 1 and cluster 3 in operating profit and net profit, in spite of significant difference in revenue. In practice, Korean biopharmaceutical firms diversified into other business segment like food and cosmetic for securing profit structure because they spent long time and huge cost for R\&D and commercialization. It implies that they are object to expand their profit stream through business diversification strategy, regardless of different business diversification paths. Industrial context of biotechnology latecomers such as Korea is difference advanced nations such as US. Biopharmaceutical firms in Korea should consider profit model from firm founding, because of deficiency of initial investment as angel or venture capital. In this sense, business diversification can be important strategy for initial profit generation to Korean biopharmaceutical firms.

Third, biopharmaceutical firms with only basic research function should cooperate with other organizations (company, university, etc.) with complementary technology assets. In context of biotechnology latecomers like Korea, most of biopharmaceutical firms is small size, young and born with one or two core technologies, thus cooperation is inevitably required for enhancing technological value as "development". The result of this study shows that the level of R\&D alliance is discriminant factor between infant and mature firms. It implies that mature firms can develop their technologies by R\&D alliances. The "research" domain originally has property as public good. However, in the "business" domain, it preferentially should focus on contributing needs of target consumers by providing new technological value and further profits of biopharmaceutical firms. For it, basic research biopharmaceutical firms should focus their competitive core technological value for business, and design their business models to rapidly acquire and learn complementary technology assets through cooperating with other organizations.

This study also has some limitations. First, there is a limitation in the clustering method. Although this study identified the business model for biopharmaceutical firms in Korea through the quantitative clustering method, a variety of methodological efforts are required. This study was analyzed using hierarchical clustering based on Ward's method as one of the methods recommended 
by Bigliardi et al. [20]. However, there are various distance measurement criteria and calculation methods in hierarchical clustering. Therefore, to enhance validity, it is necessary to compare a variety of methods in the future.

Second, the assumptions on the business model in this study are quite restrictive. Although this study selected criteria based on existing literature, more detailed criteria are still required to distinguish the business model further. We considered that it would be more necessary to capture the distinctive features of business models in latecomer countries than identifying more business models. However, characterizing more business models through detailed criteria is also an important issue for subsequent research. This study implicitly assumes that one firm has one business model. In fact, however, firms can adopt multiple business models simultaneously [61] or the model can even change over time [41]. Therefore, it will be interesting to monitor the transition or persistence of business model based on a panel data.

Third, the performances compared are limited to quantitative values. We compared the financial and innovation performances between clusters. However, larger and older firms tend to have more patents and revenues. Therefore, comparisons of ratio indicators such as revenue per employee can be made. By comparing these qualitative indicators, it is possible to discuss the economic and innovation efficiency of each cluster.

Author Contributions: All authors worked collectively and significantly contributed to this paper. conceptualization, C.S. and K.S.; methodology, K.S.; validation, C.S.; writing, C.S. and K.S.

Funding: This work was supported by Korea Institute for Advancement of Technology (KIAT) grant funded by the Korea Government (MOTIE) (The Human Resources Development Program for Creative Industry Convergence Specialist).

Conflicts of Interest: The authors declare no conflict of interest.

\section{References}

1. Casadesus-Masanell, R.; Ricart, J.E. From strategy to business models and onto tactics. Long Range Plan. 2010, 43, 195-215. [CrossRef]

2. Boni, A.A. Emerging business models and strategies to accelerate innovation in the biopharmaceutical industry. J. Commerc. Biotechnol. 2016, 22, 53-59. [CrossRef]

3. Gautam, A.; Pan, X. The changing model of big pharma: Impact of key trends. Drug Discov. Today 2016, 21, 379-384. [CrossRef]

4. Pisano, G.P. Science Business: The Promise, the Reality, and the Future of Biotech; Harvard Business School Press: Boston, MA, USA, 2006.

5. Sabatier, V.; Mangematin, V.; Rousselle, T. From recipe to dinner: Business model portfolios in the European biopharmaceutical industry. Long Range Plan. 2010, 43, 431-447. [CrossRef]

6. Niosi, J.; McKelvey, M. Relating business model innovations and innovation cascades: The case of biotechnology. J. Evol. Econ. 2018, 28, 1081-1109. [CrossRef] [PubMed]

7. Shin, K.; Park, G.; Choi, J.Y.; Choy, M. Factors affecting the survival of SMEs: A study of biotechnology firms in Korea. Sustainability 2017, 9, 108. [CrossRef]

8. Malerba, F.; Orsenigo, L. The evolution of the pharmaceutical industry. Bus. Hist. 2015, 57, 664-687. [CrossRef]

9. Carayannis, E.G.; Sindakis, S.; Walter, C. Business model innovation as lever of organizational sustainability. J. Technol. Transf. 2015, 40, 85-104. [CrossRef]

10. Cheah, S.; Ho, Y.P. Coworking and sustainable business model innovation in young firms. Sustainability 2019, 11, 2959. [CrossRef]

11. Evans, S.; Vladimirova, D.; Holgado, M.; Van Fossen, K.; Yang, M.; Silva, E.A.; Barlow, C.Y. Business model innovation for sustainability: Towards a unified perspective for creation of sustainable business model. Bus. Strat. Environ. 2017, 26, 597-608. [CrossRef]

12. Teece, D.J. Business models, business strategy and innovation. Long Range Plan. 2010, 43, 172-194. [CrossRef]

13. Zott, C.; Amit, R. Business model design: An activity system perspective. Long Range Plan. 2010, 43, 216-226. [CrossRef] 
14. Lehoux, P.; Daudelin, G.; Williams-Jones, B.; Denis, J.L.; Longo, C. How do business model and health technology design influence each other? Insights from a longitudinal case study of three academic spin-offs. Res. Policy 2014, 43, 1025-1038. [CrossRef]

15. Afuah, A.; Tucci, C.L. Internet Business Models and Strategies: Text and Cases; McGraw-Hill/Irwin: Boston, MA, USA, 2001.

16. Afuah, A. Business Models: A Strategic Management Approach, 1st ed.; McGraw-Hill/Irwin: New York, NY, USA, 2004.

17. Chesbrough, H.; Rosenbloom, R.S. The role of the business model in capturing value from innovation: Evidence from Xerox Corporation's technology spin-off companies. Ind. Corp. Chang. 2002, 11, 529-555. [CrossRef]

18. Shafer, S.M.; Smith, H.J.; Linder, J.C. The power of business models. Bus. Horizons 2005, 48, $199-207$. [CrossRef]

19. Zott, C.; Amit, R.; Massa, L. The business model: Recent developments and future research. J. Manag. 2011, 37, 1019-1042.

20. Bigliardi, B.; Nosella, A.; Verbano, C. Business models in Italian biotechnology industry: A quantitative analysis. Technovation 2005, 25, 1299-1306. [CrossRef]

21. Willemstein, L.; van der Valk, T.; Meeus, M.T. Dynamics in business models: An empirical analysis of medical biotechnology firms in the Netherlands. Technovation 2007, 27, 221-232. [CrossRef]

22. Konde, V. Biotechnology business models: An Indian perspective. J. Commer. Biotechnol. 2009, 15, $215-226$. [CrossRef]

23. Lambert, S.C. The importance of classification to business model research. J. Bus. Models 2015, 3, 49-61.

24. Li, X.; Qiao, H.; Wang, S. Exploring evolution and emerging trends in business model study: A co-citation analysis. Scientometrics 2017, 111, 869-887. [CrossRef]

25. Markides, C.; Charitou, C.D. Competing with dual business models: A contingency approach. Acad. Manag. Perspect. 2004, 18, 22-36. [CrossRef]

26. Smith, W.K.; Binns, A.; Tushman, M.L. Complex business models: Managing strategic paradoxes simultaneously. Long Range Plan. 2010, 43, 448-461. [CrossRef]

27. Calia, R.C.; Guerrini, F.M.; Moura, G.L. Innovation networks: From technological development to business model reconfiguration. Technovation 2007, 27, 426-432. [CrossRef]

28. Doganova, L.; Eyquem-Renault, M. What do business models do? Innovation devices in technology entrepreneurship. Res. Policy 2009, 38, 1559-1570. [CrossRef]

29. Mathews, J.A. Competitive advantages of the latecomer firm: A resource-based account of industrial catch-up strategies. Asia Pac. J. Manag. 2002, 19, 467-488. [CrossRef]

30. Hobday, M.; Rush, H.; Bessant, J. Approaching the innovation frontier in Korea: The transition phase to leadership. Res. Policy 2004, 33, 1433-1457. [CrossRef]

31. Hu, M.; Hsu, W.; Wu, C. Why is growth more difficult to achieve for biopharmaceutical latecomer firms? Evidence from Taiwan. Sci. Technol. Soc. 2018, 23, 388-417. [CrossRef]

32. Hwang, S.W. Middle-ground players in dynamic imitative markets: Global entry strategies of Korean firms in the biosimilars market. Technol. Anal. Strateg. 2017, 29, 325-338. [CrossRef]

33. Lazonick, W.; Tulum, Ö. US biopharmaceutical finance and the sustainability of the biotech business model. Res. Policy 2011, 40, 1170-1187. [CrossRef]

34. Spieth, P.; Schneider, S. Business model innovativeness: Designing a formative measure for business model innovation. J. Business Econ. 2016, 86, 671-696. [CrossRef]

35. Nosella, A.; Petroni, G.; Verbano, C. How do Italian biotech startups survive? J. Bus. Chem. 2006, 3, 7-14.

36. March-Chordà, I.; Yagüe-Perales, R.M. Biopharma business models in Canada. Drug Discov. Today 2011, 16, 654-658. [CrossRef] [PubMed]

37. Suurna, M. The developments in the business models of biotechnology in the Central and Eastern European countries: The example of Estonia. J. Commer. Biotechnol. 2011, 17, 84-108. [CrossRef]

38. McKelvey, M. Health biotechnology: Emerging business models and institutional drivers. In The Bioeconomy to 2030: Designing a Policy Agenda; OECD International Futures Programmes: Paris, France, 2008.

39. Burns, L.R. The Business of Healthcare Innovation; Cambridge University Press: Cambridge, UK, 2005.

40. Casper, S. Institutional adaptiveness, technology policy, and the diffusion of new business models: The case of German biotechnology. Organ. Stud. 2000, 21, 887-914. [CrossRef] 
41. Demil, B.; Lecocq, X. Business model evolution: In search of dynamic consistency. Long Range Plan. 2010, 43, 227-246. [CrossRef]

42. Fisken, J.; Rutherford, J. Business models and investment trends in the biotechnology industry in Europe. J. Commer. Biotechnol. 2002, 8, 191-199. [CrossRef]

43. Pammolli, F.; Magazzini, L.; Riccaboni, M. The productivity crisis in pharmaceutical R\&D. Nat. Rev. Drug Discov. 2011, 10, 428-438.

44. Hunter, J.; Stephens, S. Is open innovation the way forward for big pharma? Nat. Rev. Drug Discov. 2010, 9, 87. [CrossRef]

45. Rusu, A.; Kuokkanen, K.; Heier, A. Current trends in the pharmaceutical industry-A case study approach. Eur. J. Pharm. Sci. 2011, 44, 437-440. [CrossRef]

46. Downs, J.B.; Velamuri, V.K. Business model innovation opportunities for the biopharmaceutical industry: A systematic review. J. Commerc. Biotechnol. 2016, 22, 19-63. [CrossRef]

47. Piachaud, B. Outsourcing technology. Res. Technol. Manag. 2005, 48, 40-46. [CrossRef]

48. Michelino, F.; Lamberti, E.; Cammarano, A.; Caputo, M. Measuring open innovation in the bio-pharmaceutical industry. Creat. Innov. Manag. 2015, 24, 4-28. [CrossRef]

49. Allarakhia, M. The successes and challenges of open-source biopharmaceutical innovation. Expert Opin. Drug Dis. 2014, 9, 459-465. [CrossRef] [PubMed]

50. Mazzola, E.; Bruccoleri, M.; Perrone, G. Open innovation and firms' performance: State of the art and empirical evidences from the bio-pharmaceutical industry. Int. J. Technol. Manag. 2016, 70, 109-134. [CrossRef]

51. Ren, S.; Su, P. Open innovation and intellectual property strategy: The catch-up processes of two Chinese pharmaceutical firms. Technol. Anal. Strateg. 2015, 27, 1159-1175. [CrossRef]

52. Science and Technology Policy Institute. 20 Years of Korean Biotech Venture: Past, Present and Challenges for Future; JeongIn I\&D Press: Seoul, Korea, 2013. (In Korean)

53. Ward, J.H., Jr. Hierarchical grouping to optimize an objective function. J. Am. Stat. Assoc. 1963, 58, $236-244$. [CrossRef]

54. Székely, G.J.; Rizzo, M.L. Hierarchical clustering via joint between-within distances: Extending Ward's minimum variance method. J. Classif. 2005, 22, 151-183. [CrossRef]

55. Hermann, B.G.; Patel, M. Today's and tomorrow's bio-based bulk chemicals from white biotechnology: A techno-economic analysis. Appl. Biochem. Biotechnol. 2007, 136, 361-388. [CrossRef]

56. Kruskal, W.H.; Wallis, W.A. Use of ranks in one-criterion variance analysis. J. Am. Stat. Assoc. 1952, 47, 583-621. [CrossRef]

57. Gibbons, J.D.; Chakraborti, S. Nonparametric Statistical Inference; Springer: Berlin/Heidelberg, Germany, 2011.

58. Dubes, R.; Jain, A.K. Clustering methodologies in exploratory data analysis. Adv. Comput. 1980, 19, $113-228$.

59. Kleinknecht, A.; Van Montfort, K.; Brouwer, E. The non-trivial choice between innovation indicators. Econ. Innov. New Technol. 2002, 11, 109-121. [CrossRef]

60. Qian, G.; Li, L. Profitability of small-and medium-sized enterprises in high-tech industries: The case of the biotechnology industry. Strateg. Manag. J. 2003, 24, 881-887. [CrossRef]

61. Winterhalter, S.; Zeschky, M.B.; Gassmann, O. Managing dual business models in emerging markets: An ambidexterity perspective. RED Manag. 2016, 46, 464-479.

(C) 2019 by the authors. Licensee MDPI, Basel, Switzerland. This article is an open access article distributed under the terms and conditions of the Creative Commons Attribution (CC BY) license (http://creativecommons.org/licenses/by/4.0/). 